\title{
Nucleoside Diphosphate Kinase A
}

National Cancer Institute

\section{Source}

National Cancer Institute. Nucleoside Diphosphate Kinase A. NCI Thesaurus. Code C17314.

Nucleoside diphosphate kinase A (152 aa, $17 \mathrm{kDa}$ ) is encoded by the human NME1 gene. This protein plays a role in nucleoside triphosphate synthesis, lipid and protein phosphorylation, apoptosis and the regulation of cell proliferation. 